\title{
Glycemia Lowering Effect of an Aqueous Extract of Hedychium coronarium Leaves in Diabetic Rodent Models
}

\author{
Ling-Shan Tse ${ }^{1}$, Po-Lin Liao ${ }^{2}$, Chi-Hao Tsai ${ }^{1,3}$, Ching-Hao Li ${ }^{4}$, Jiunn-Wang Liao ${ }^{5}(\mathbb{D}$, \\ Jaw-Jou Kang ${ }^{2}$ and Yu-Wen Cheng ${ }^{1, * \mathbb{D}}$ \\ 1 School of Pharmacy, College of Pharmacy, Taipei Medical University, Taipei 110, Taiwan; \\ zoetsels@gmail.com (L.-S.T.); d01447001@ntu.edu.tw (C.-H.T.) \\ 2 Institute of Food Safety and Health Risk Assessment, School of Pharmaceutical Sciences, \\ National Yang-Ming University, Taipei 112, Taiwan; plliao0825@gmail.com (P.-L.L.); \\ jjkang@ym.edu.tw (J.-J.K.) \\ 3 Institute of Toxicology, College of Medicine, National Taiwan University, Taipei 100, Taiwan \\ 4 Department of Physiology, School of Medicine, Graduate Institute of Medical Sciences, College of Medicine, \\ Taipei Medical University, Taipei 110, Taiwan; bros22@tmu.edu.tw \\ 5 Graduate Institute of Veterinary Pathobiology, National Chung Hsing University, Taichung 402, Taiwan; \\ jwliao@dragon.nchu.edu.tw \\ * Correspondence: ywcheng@tmu.edu.tw; Tel.: +886-2-2736-1661 (ext. 6123); Fax: +886-2-2737-4622
}

Received: 7 February 2019; Accepted: 11 March 2019; Published: 14 March 2019

\begin{abstract}
Hedychium coronarium has a long history of use worldwide as a food and in folk medicine. In this study, we aimed to investigate the effect of an aqueous extract of $H$. coronarium leaves (HC) on type 2 diabetes mellitus (T2DM). Two types of animal models were used in this study: Streptozotocin (STZ)-induced T2DM (Wistar rats; $N=8$ ) and C57BKSdb/db mice $(N=5)$. After treatment with HC for 28 days, glucose tolerance improved in both of the diabetic animal models. As significant effects were shown after 14 days of treatment in the STZ-induced T2DM model, we carried out the experiments with it. After 28 days of treatment with HC, the levels of cholesterol, triglyceride, high-density lipoprotein, and low-density lipoprotein were significantly improved in the STZ-induced T2DM model. The lesions degree of islet $\beta$-cells was decreased after the HC treatment. Although the insulin level increased moderately, the aldosterone level was significantly decreased in the HC-treated groups, suggesting that aldosterone might play an important role in this effect. In summary, HC is a natural product and it is worth exploring its effect on T2DM.
\end{abstract}

Keywords: Hedychium coronarium; type 2 diabetes; aldosterone; streptozotocin; metabolic syndrome; folk medicine

\section{Introduction}

Diabetes is a chronic progressive disease and one of the ten leading causes of death worldwide [1]. In the past three decades, the prevalence of type 2 diabetes mellitus (T2DM) has increased dramatically in countries of all income levels. Over time, diabetes causes various complications: It starts by damaging blood vessels, reducing the blood flow, with sequelae that may be macrovascular (heart attack, stroke, and heart failure) [2-4], or microvascular (blindness [5-7] and kidney failure [8]), or causing neuropathies (lower limb amputation). When diabetes is not controlled, not only is the patient quality of life affected and present a burden on medical resources, but the condition may also lead to death. In 2015, the World Health Organization (WHO) declared diabetes as one of the four priority noncommunicable diseases (NCDs) and established a diabetes program to 
reduce the impact of diabetes by 2020. The management of diabetes consists of two main steps: Preventing (decreasing the possible risk factors) and stabilizing the disease progress (early diagnosis, medication, and intake management) [9]. To stabilize the disease, it is crucial to adopt effective measures for surveillance and treatment strategies (pharmacologic and non-pharmacologic interventions) [10,11]. In addition to the development of novel drugs, the use of traditional medicine and food supplements for the treatment of T2DM should be investigated.

Traditional medicine (also known as folk medicine) has been used globally for centuries. Although the medicinal properties of resources such as mollusks and plants rely on the inheritance of experience, they have been gradually accepted in modern medicine. A food supplement is a dosed formulation of food and herbs, and provides medical benefits through its biologically active components [12]. Therefore, both traditional medicine and food supplements can be part of the treatment strategies for diabetes.

Extensive research has focused on the rhizome of Hedychium coronarium. However, the pharmacological benefits of $H$. coronarium leaf appear overlooked. $H$. coronarium is highly accessible and its leaf is a common vegetable in Taiwan. Therefore, in this study, two types of animal models were used to evaluate the lowering blood glucose level benefits of an aqueous extract of H. coronarium leaves (HC). A new supplement was developed, called SugarOut (SO), which contained $15 \%$ red yeast rice (RYR) and $7.2 \%$ H. coronarium. Red yeast rice (RYR) is a fermentation product that is traditionally used in East Asia to dye and preserve food. Its main pharmacologically active compound is monacolin-K (also called lovastatin).

H. coronarium (also called ginger lily), a plant approximately 1-3 $\mathrm{m}$ in height and has a long history of use in food and traditional folk medicine. For example, it is used in beauty products in Hawaii and Japan, as an essential oil in Vietnam, and as a vegetable in Malaysia. It can help ease indigestion, inflammation, insomnia, and pain in the muscles, joints, and abdomen $[13,14]$. In Brazil, H. coronarium leaf is considered a diuretic [15] and is used for the treatment of hypertension [16]. In India, the rhizome is used for the treatment of diabetes [17]. Many different bioactive compounds have been isolated from H. coronarium and their pharmacological effects have been established. For example, diterpenoids and a diarylheptanoid showed anti-angiogenic activity and suppressed the growth of different cancer cell types [18]. Coronarin D shows active resistance to Gram-positive bacteria and fungi [19], induces G2/M arrest, apoptosis, and autophagy [20]. Hedychilactones A, B, and C inhibit increases in nitric oxide (NO) production and the induction of inducible NO synthase [21]. Quercetin-3-O-glucuronide (Q3GA) has been reported to show beneficial effects in the reduction and prevention of various diseases, including neurodegenerative diseases, and to exert anti-inflammatory and antioxidant activities [22].

\section{Material and Methods}

\subsection{Preparation of Aqueous Extract of Hedychium coronarium and SugarOut}

The HC (containing 1.4\% Q3GA) was a deep brown powder. Fresh overground parts (leaves and stems) of $H$. coronarium were collected in Pingtung, Taiwan. The dried leaves and stems of H. coronarium $(100 \mathrm{~kg})$ were extracted in $100 \%$ water at room temperature $\left(25-35^{\circ} \mathrm{C}\right)$. The $100 \%$ water extracts were concentrated in vacuo and then lyophilized to obtain a dark brown powder ( $8.4 \%$ yield).

$\mathrm{SO}$ was a prototype supplement (dark red powder) developed from $\mathrm{H}$. coronarium that assisted with blood glucose regulation. It contained two main extracts: The RYR extract $(15 \%)$ and the HC $(7.2 \%)$. The two main bioactive compounds were monacolin K $1.8 \mathrm{mg}( \pm 20 \%)$ and Q3GA $0.6 \mathrm{mg}( \pm 20 \%)$.

Both test substances were provided by Vinovo Inc. The $\mathrm{HC}$ was stored at $4{ }^{\circ} \mathrm{C}$ and the SO was stored at room temperature. Both test substances were freshly dissolved in distilled water and administered by oral gavage daily to all rodents in the morning. 


\subsection{Animal Study}

The Streptozotocin (STZ)-induced T2DM model was established in Wistar rats obtained from BioLASCO Ltd. (Taipei, Taiwan) and C57BKS ${ }^{\mathrm{db} / \mathrm{db}}$ mice (termed $\mathrm{db} / \mathrm{db}$ here) were obtained from the National Laboratory Animal Center (Taipei, Taiwan). All procedures involving the use of animals were in compliance with the Guide for the Care and Use of Laboratory Animals (Press, 1996) and approved by the Institutional Animal Care and Use Committee at our institution (Approval no. LAC-2016-0168). The preliminary data suggested that the effective dose of SO was $246 \mathrm{mg} / \mathrm{kg}$ in the $\mathrm{db} / \mathrm{db}$ model. As bioavailability differs between rodent species, based on FDA Guidance, the conversion factors for the rat Wistar STZ model and the mouse $\mathrm{db} / \mathrm{db}$ model were 6.2 and 12.3, respectively [23]. Therefore, $124 \mathrm{mg} / \mathrm{kg}$ SO was administered to the STZ-T2DM rats and $246 \mathrm{mg} / \mathrm{kg}$ was administered to the $\mathrm{C} 57 \mathrm{BKS} \mathrm{db}^{\mathrm{db}}$ mice by oral gavage.

\subsection{1. $\mathrm{C}^{2} \mathrm{BKKS} \mathrm{db}^{\mathrm{db} / \mathrm{db}}$ Mice (db/db Model)}

The C57BKS $\mathrm{db}^{\mathrm{db}}$ mouse is a model of diabetes with a spontaneous mutation (Lepr ${ }^{\mathrm{db}}$ ) resulting in morbid obesity, chronic hyperglycemia, pancreatic beta cell atrophy, and low insulin [24]. The diabetes model is determined to be well-established when the blood glucose level is $>230 \mathrm{mg} / \mathrm{dL}$ after $18 \mathrm{~h}$ fasting. Fifteen male mice (25-30 g) were divided into the following three groups $(N=5)$ : Control (treated with distilled water); HC (17.71 mg/kg); and SO (246 mg/kg) [23] (Figure 1).

$\mathrm{C57BKS}^{\mathrm{db} / \mathrm{db}}$ mice (3 groups ; $\left.\mathrm{N}=5\right)$

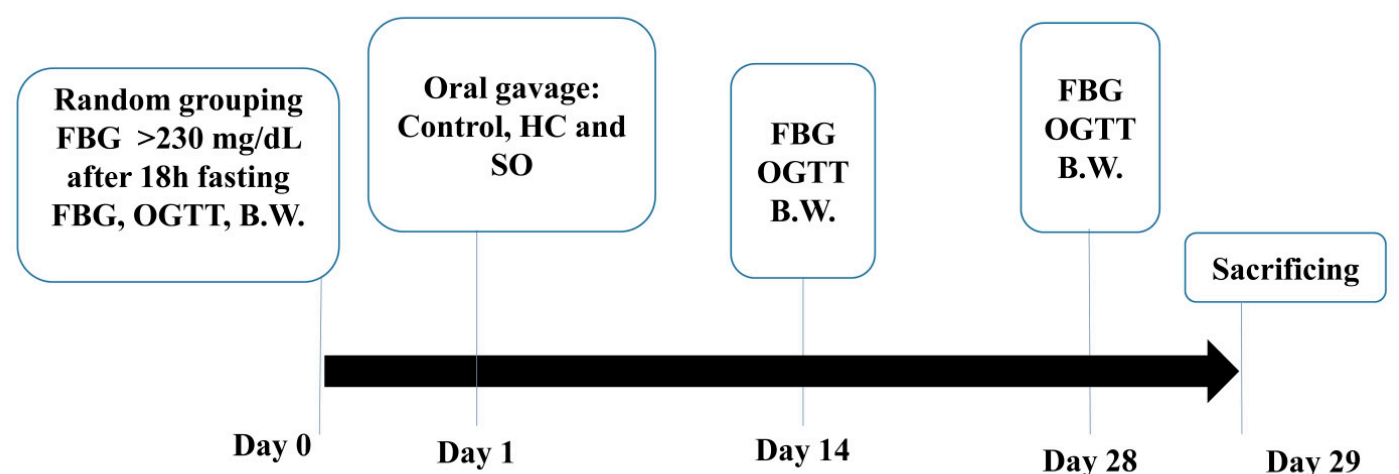

Figure 1. Study procedure for the C57BKS $\mathrm{db}^{\mathrm{db}}$ mice (termed $\mathrm{db} / \mathrm{db}$ here). Fifteen male $\mathrm{db} / \mathrm{db}$ mice were randomly divided into three groups $(N=5)$ : Control, treatment with Hedychium coronarium leaves (HC), or SugarOut (SO) supplement. FBG, fasting blood glucose; OGTT, oral glucose tolerance test; B.W., Body Weight.

\subsubsection{STZ-Induced Type 2 Diabetes Model}

T2DM was induced in 24 6-week-old male Wistar rats by the administration of $65 \mathrm{mg} / \mathrm{kg}$ STZ in $0.1 \mathrm{M}$ citrate solution $15 \mathrm{~min}$ after nicotinamide injection $(230 \mathrm{mg} / \mathrm{kg}$ in saline; intraperitoneally) [25-28]. The rats were caged (two animals per cage) in a controlled environment (12 h light/dark cycle, $23 \pm 1{ }^{\circ} \mathrm{C}$, and $39-43 \%$ relative humidity). The fasting glucose level was measured 1 week after the injections. The T2DM model was determined to be well-established when the blood glucose level was $>230 \mathrm{mg} / \mathrm{dL}$ after $18 \mathrm{~h}$ of fasting. After T2DM was established, the rats were randomly divided into three groups of eight rats: Control; $\mathrm{HC}(8.928 \mathrm{mg} / \mathrm{kg})$; and SO $(124 \mathrm{mg} / \mathrm{kg})$. An additional eight Wistar rats were used as the sham control (Figure 2). 
6-week old male wistar ( 3 groups; $\mathrm{N}=8$ )

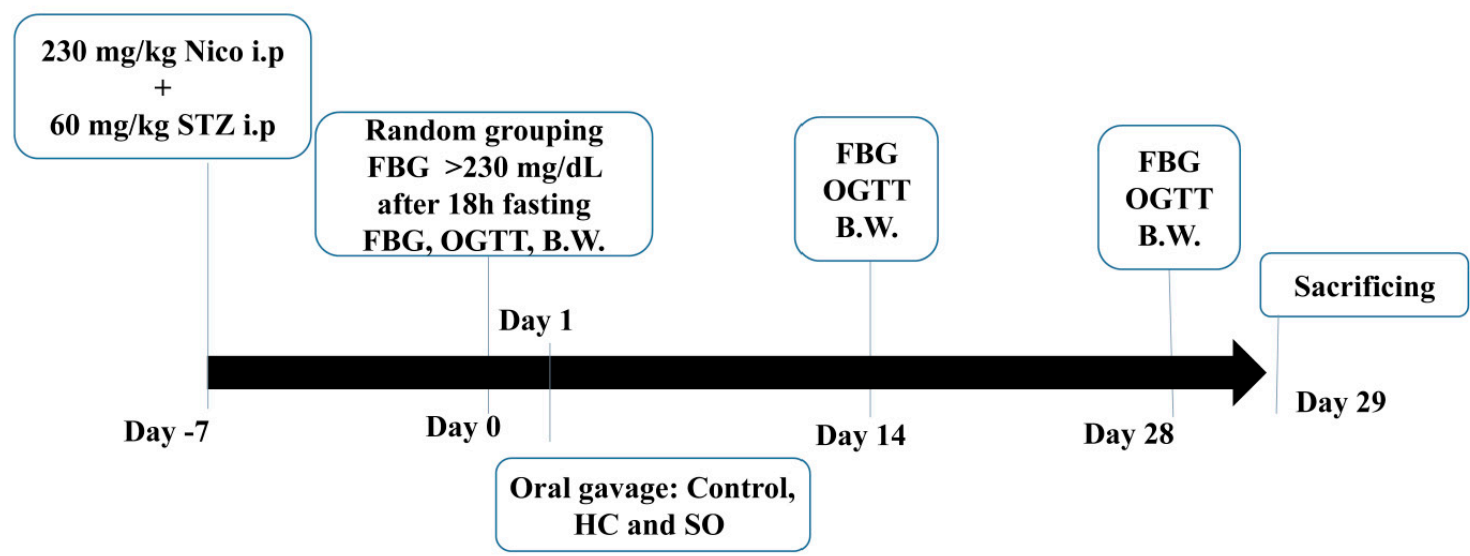

Figure 2. Study procedure for Streptozotocin (STZ)-induced type 2 diabetes rats. Diabetes was induced in 24 male Wistar rats, which were then randomly divided into three groups (Control, $\mathrm{HC}$, and $\mathrm{SO} ; \mathrm{N}=8$ ).

\subsection{Fasting Blood Glucose and Oral Glucose Tolerance Test}

All rodents were administered the test substances daily. The body weight and fasting blood glucose (FBG) was measured on day 0,14 , and 28 . The oral glucose tolerance test (OGTT) was performed on day 14 and 28. Each rodent fasted for $16 \mathrm{~h}$ before the FBG measurement. The test substances were administered $30 \mathrm{~min}$ before glucose challenge $(1 \mathrm{~g} / \mathrm{kg})$, and then the blood glucose was tested $0,30,60,90$, and $120 \mathrm{~min}$ after the challenge by using IME-DC glucose test strips (IME-DC, Berlin, Germany).

\subsection{Aldosterone and Insulin Levels}

Serum samples were collected on day 29 after the T2DM rats were sacrificed. Insulin was quantified through the measurement of the optical density at $450 \mathrm{~nm}$ by using a Mercodia Ultrasensitive rat insulin ELISA kit (Mercodia AB, Uppsala, Sweden) and aldosterone was quantified through the measurement of the optical density at $405 \mathrm{~nm}$ corrected by the measurement at $590 \mathrm{~nm}$ by using an aldosterone ELISA kit (ab136933; Abcam, Cambridge, UK).

\subsection{Histopathological Analysis}

The pancreas was excised from T2DM rats after they were sacrificed on day 29. The samples were fixed in $10 \%$ neutral buffered formalin, and then prepared and examined by a professional pathologist from the Graduate Institute of Veterinary Pathobiology, National Chung Hsing University, Taichung, Taiwan. The severity of lesions in the islet $\beta$-cells of the pancreas was graded according to the methods described by Shackelford et al. [29]. The degree of lesions was graded from one to five, depending on severity: $1=$ minimal $(<1 \%) ; 2=$ slight $(1-25 \%) ; 3=$ moderate $(26-50 \%) ; 4=$ moderately severe $(51-75 \%) ; 5=$ severe $/$ high $(76-100 \%)$.

\subsection{Serum Biochemical Analysis}

Blood samples from the T2DM rats were collected at the end of the 28-day oral administration period and then analyzed by using an Express Plus automatic clinical chemistry analyzer (Siemens Healthineers, Erlangen, Germany).

\subsection{Statistical Analysis}

All values are expressed as the mean \pm standard deviation (SD) in tables and the mean \pm standard error (SE) in figures. The comparisons between groups were performed by one-way analysis of 
variance (ANOVA) followed by Scheffe multiple comparison tests using SPSS Statistical Software (IBM, New York, NY, USA). Values of $p<0.05$ were considered significant.

\section{Results}

3.1. HC Improved Fasting Blood Glucose and Glucose Tolerance in Both Diabetic Animal Models After 28 Days of Treatment

In the $\mathrm{db} / \mathrm{db}$ model, after oral gavage of $\mathrm{SO}$ and $\mathrm{HC}$, mice gained weight slower than the control group (Figure 3A). The HC decreased the FBG (Figure 3B) and increased the glucose tolerance after treatment for 14 days (Figure 3C); a significant difference was observed after treatment for 28 days (Figure 3D). SO also affected the FBG and glucose tolerance, however, the effects of SO were not as remarkable as those of the HC.

(A)

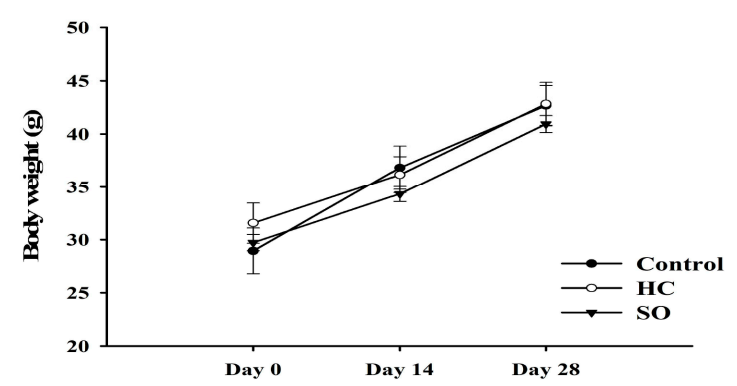

(C)

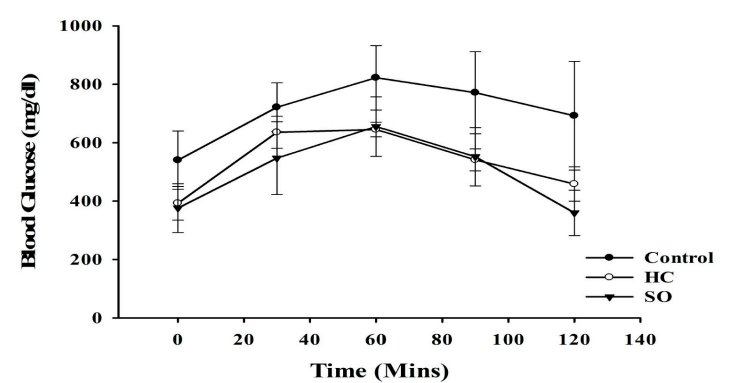

(B)

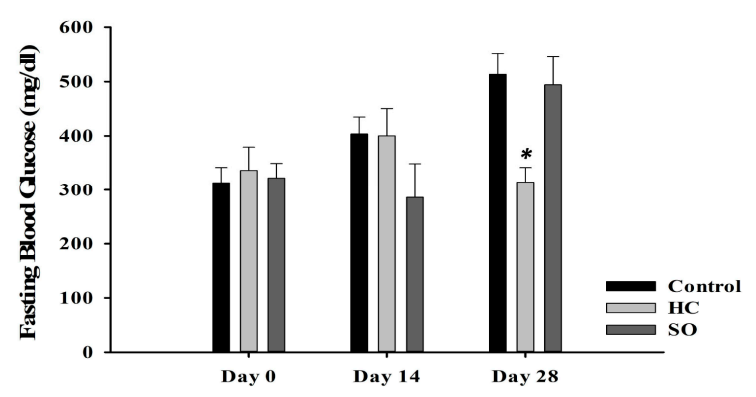

(D)

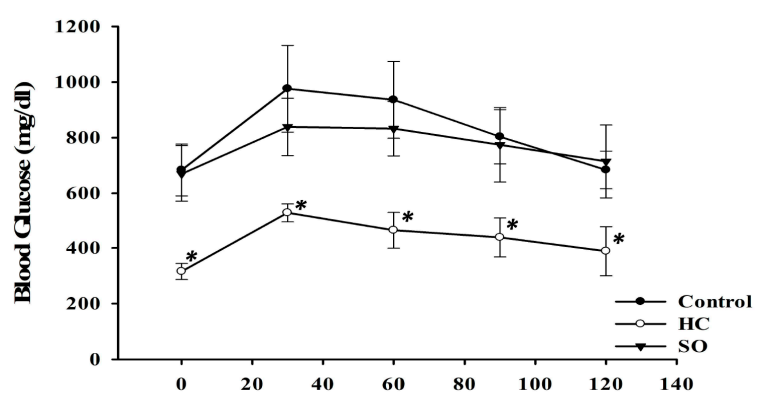

Figure 3. Effects of $\mathrm{HC}$ and $\mathrm{SO}$ in $\mathrm{C} 57 \mathrm{BKS} \mathrm{Sb}^{\mathrm{db} / \mathrm{db}}$ mice $(N=5)$. (A) Changes in body weight. (B) Changes in fasting blood glucose (FBG) after treatment with $\mathrm{HC}$ and $\mathrm{SO}$ for 14 days and 28 days. (C) Oral glucose tolerance test (OGTT) after administration of $\mathrm{HC}$ and $\mathrm{SO}$ for 14 days. (D) OGTT after administration of HC and SO for 28 days. Significant difference between the control-treated group at ${ }^{*} p<0.05$, by one-way ANOVA.

In general, the STZ-induced T2DM model shows a significant weight reduction [30]. In this study, after oral gavage of $\mathrm{SO}$ and $\mathrm{HC}$ for 28 days, the body weights of mice receiving $\mathrm{HC}$ and SO was increased compared to that in the control group (Figure 4A) and the FBG was slightly lower in the $\mathrm{SO}$ group on day 28 (Figure 4B). After 14 days of oral administration of $\mathrm{HC}$ and SO, the blood glucose level in the $\mathrm{HC}$ and $\mathrm{SO}$ groups was significantly decreased compared with that in the control group at 60, 90, and $120 \mathrm{~min}$ after intake of $1 \mathrm{~g} / \mathrm{kg}$ glucose (Figure 4C; $p$-value in Supplementary Table S1). After administration of HC and SO for 28 days (Figure 4D), the glucose level in the SO group was significantly lower than that in control group from 30 to $120 \mathrm{~min}$ after the intake of $1 \mathrm{~g} / \mathrm{kg}$ glucose ( $p$-value in Supplementary Table S1), however, the HC only resulted in a significant difference at $30 \mathrm{~min}$ after glucose intake. The area under the curve (AUC) of both the SO and HC groups was significantly lower than that of the control group (Table 1). These results suggested that HC could improve the FBG and glucose tolerance after 28 days in the $\mathrm{db} / \mathrm{db}$ mice. A notable increase in glucose tolerance was observed in both the $\mathrm{HC}$ and $\mathrm{SO}$ groups after 14 days of administration, and a significant 
increase in glucose tolerance was observed after 28 days of administration in the T2DM model. Therefore, the following experiments focused on the STZ-induced T2DM model.

(A)

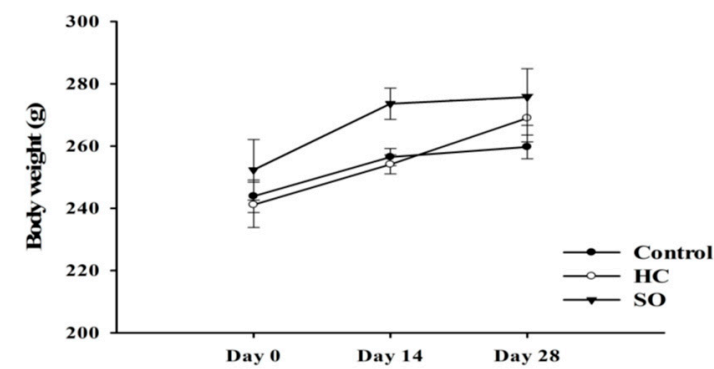

(C)

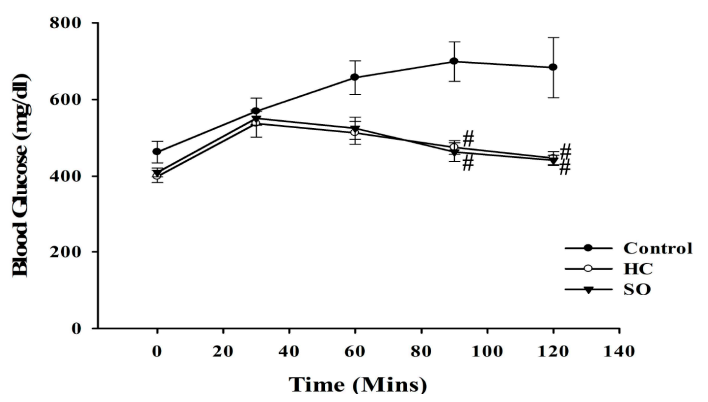

(B)

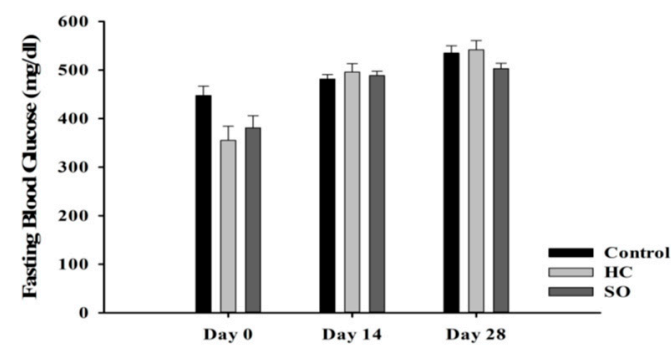

(D)

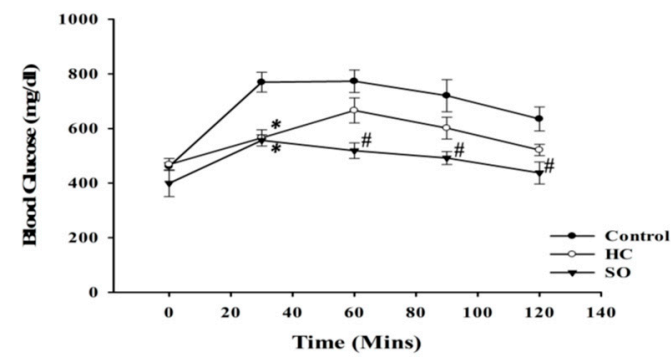

Figure 4. STZ-induced type 2 diabetes model (T2DM; $N=8$ ) after the administration of $\mathrm{HC}$ and SO for 14 and 28 days. (A) Changes in body weight. (B) Changes in fasting blood glucose. (C) OGTT after administration of HC and SO for 14 days. (D) OGTT after administration of HC and SO for 28 days. Significant difference between control-treated group at ${ }^{*} p<0.05$, \# $p<0.01$ by one-way ANOVA.

Table 1. Area under the curve (AUC) of blood glucose in the oral glucose tolerance test (OGTT).

\begin{tabular}{ccc}
\hline AUC & 14 Days & 28 Days \\
\hline Sham & $8898.75 \pm 1816.12$ & $1666.88 \pm 3399.66$ \\
Control & $23,578.13 \pm 9636.76$ & $32,130.00 \pm 8133.19$ \\
H. coronarium leaves (HC) & $11,730.00 \pm 5959.70$ & $14,979.38 \pm 5656.03 *$ \\
SugarOut (SO) & $10,301.25 \pm 5884.57$ & $11,945.63 \pm 13,782.89 * *$
\end{tabular}

Sham = wild-type Wistar rats treated with distilled water. $N=8$ in each group. The data are expressed as the mean \pm standard deviation (SD). Significant difference between the control-treated group at * $p<0.05$, ** $p<0.01$ by one-way ANOVA.

\subsection{H. coronarium Attenuated STZ-Induced Pancreatic Damage and Ameliorated the Markers of Metabolic Syndrome}

The levels of cholesterol, triglyceride, high-density lipoprotein (HDL), and low-density lipoprotein (LDL) were significantly decreased in the STZ-induced T2DM model compared with the control group. In the HC group, creatinine and blood urea nitrogen (BUN) were lower than the control group and similar to the sham group. The SO group did not show any significant differences compared with the control group, but the laboratory results tended to be similar to those in the sham group (Tables 2 and S2). STZ caused a severe decrease in islet $\beta$-cells (Figure 5B) and severe atrophy of acinar cells in the pancreas (Figure 5B; Figure 6B). Biopsy sections of the HC (Figure 5C; Figure 6C) and SO (Figure 5D; Figure 6D) groups showed that the morphology of the islet $\beta$-cells and acinar cells of the pancreas tended to be similar to the sham group (Figure 5A; Figure 6A). According to the degree of lesions (Table 3$)$ after 28 days treatment, HC (0.79-fold) and SO (0.68-fold) prevented the decrease of islet cells and the atrophy of acinar cells (HC, 0.85-fold; SO 0.70-fold). HC and SO had 
moderate protective effects against the damage caused by STZ and regulated lipid markers (Table 2). However, the mechanism underlying the beneficial effects of HC on T2DM remains to be elucidated.

Table 2. Biochemical analysis of T2DM rat model after treatment with HC and SO for 28 days.

\begin{tabular}{cccccc}
\hline Group & & Sham & Control & HC & SO \\
\hline Number of Animals & & 8 & 8 & 8 & 8 \\
Cholesterol & $\mathrm{mg} / \mathrm{dL}$ & $69.28 \pm 25.71$ & $161.50 \pm 63.79$ & $76.63 \pm 15.30^{* *}$ & $111.63 \pm 51.48$ \\
Triglycerides & $\mathrm{mg} / \mathrm{dL}$ & $58.13 \pm 23.93$ & $753.38 \pm 434.92$ & $105.13 \pm 33.31^{* *}$ & $480.75 \pm 410.14$ \\
HDL & $\mathrm{mmol} / \mathrm{L}$ & $27.13 \pm 12.16$ & $33.38 \pm 13.23$ & $42.75 \pm 13.10$ & $38.50 \pm 12.31$ \\
LDL & $\mathrm{mmol} / \mathrm{L}$ & $7.63 \pm 1.77$ & $37.63 \pm 19.83$ & $10.50 \pm 2.56^{* *}$ & $22.25 \pm 21.02$ \\
\hline
\end{tabular}

HDL: low-density lipoproteins cholesterol; LDL: low-density lipoproteins cholesterol. Data are expressed as the mean \pm SD. Significant difference between the control-treated group at $* * p<0.01$ by one-way ANOVA.

(A)

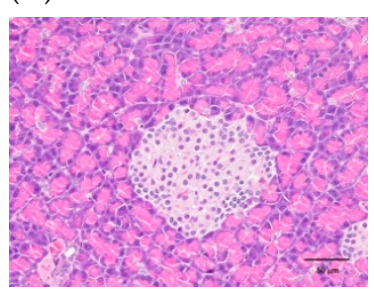

(B)

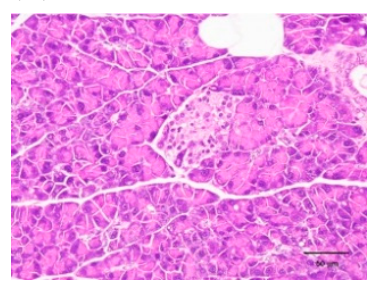

(C)

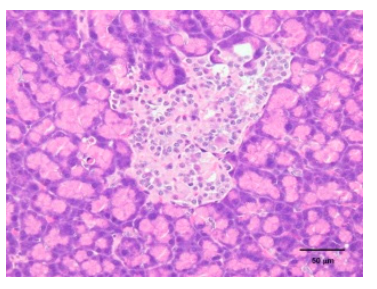

(D)

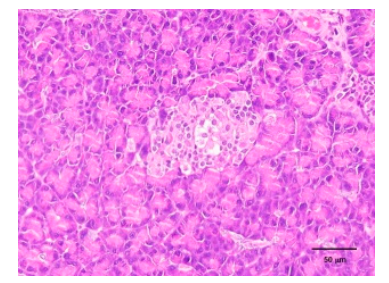

Figure 5. Histopathological changes by hemotoxylin and eosin $(\mathrm{H} \& \mathrm{E})$ staining $(400 \times)$ of the islets of the pancreas in rats with STZ-induced $\beta$-cell toxicity. (A) Sham control. Normal architecture of the $\beta$-cells in the islets of the pancreas. STZ induced a slight to moderate/severe decrease of $\beta$-cells in the islets of the pancreas in (B) T2DM control model. (C) T2DM model treated with HC for 28 days. (D) T2DM model treated with SO for 28 days. Scale bar $=50 \mu \mathrm{m}$.

(A)

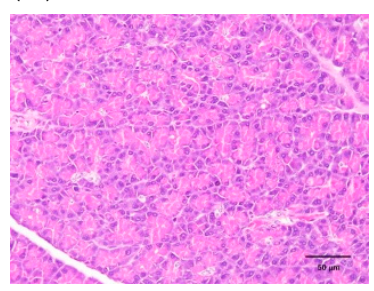

(B)

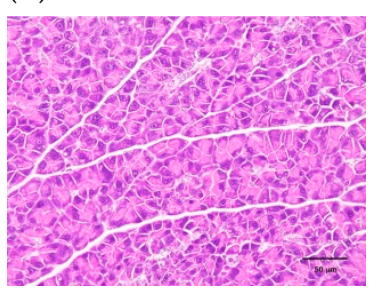

(C)

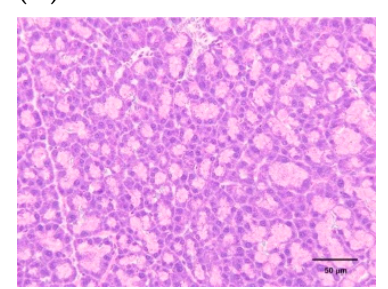

(D)

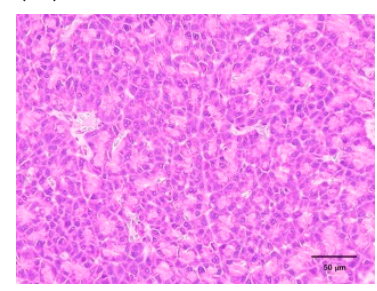

Figure 6. Histopathological changes ( $\mathrm{H} \& \mathrm{E}$ staining, 400×) of the acinar cells in the pancreas in rats with STZ-induced $\beta$-cell toxicity. (A) Sham control. Normal architecture of the $\beta$-cells in the islets of the pancreas. STZ induced a slight to moderate/severe decrease of $\beta$-cells in the islets of the pancreas in (B) T2DM control model. (C) T2DM model treated with HC for 28 days. (D) T2DM model treated with SO for 28 days. Scale bar $=50 \mu \mathrm{m}$.

Table 3. Degree of lesions in the pancreas of the T2DM model animals after treatment with HC and SO for 28 days.

\begin{tabular}{cccc}
\hline Pancreas & Control & HC & SO \\
\hline Decrease, $\beta$-cell, islet, focal & $3.80 \pm 0.45$ & $3.00 \pm 0.71$ & $2.60 \pm 0.55$ \\
Atrophy, acinar cell, diffuse & $4.00 \pm 0.00$ & $3.40 \pm 0.89$ & $2.80 \pm 1.10$ \\
\hline
\end{tabular}

The degree of lesions was graded from one to five depending on severity: $1=$ minimal $(<1 \%) ; 2=\operatorname{slight}(1-25 \%)$; $3=$ moderate $(26-50 \%) ; 4=$ moderate/severe $(51-75 \%) ; 5=$ severe $/$ high $(76-100 \%)$.

\subsection{HC Altered Insulin and Aldosterone Content in Blood}

Insulin levels in the HC (1.32-fold) and SO (1.29-fold) groups increased moderately compared with the control group (Figure 7). Much research has shown that the renin-angiotensin-aldosterone system (RAAS) plays a critical role in diabetes [31-33]. In our previous study, the oral administration 
of $H$. coronarium aqueous extract $(3 \mathrm{~g} / \mathrm{kg}$ ) to Sprague Dawley rats for 90 days, resulted in a decrease of aldosterone levels in the serum. Therefore, we measured the aldosterone level in the present study. Aldosterone was significantly decreased in both HC (0.59-fold) and SO (0.61-fold) groups compared with that in the control group (Figure 8).

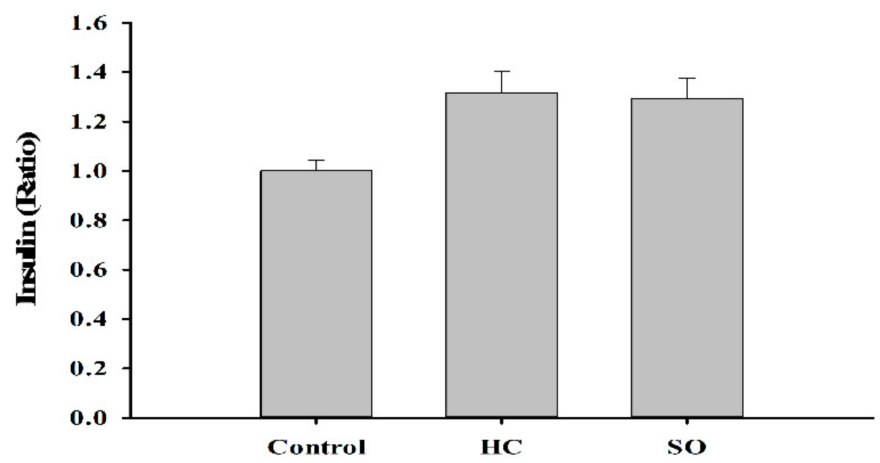

Figure 7. Insulin level in T2DM model rats after 28 days of treatment. No significant difference was found between the control-treated group by one-way ANOVA.

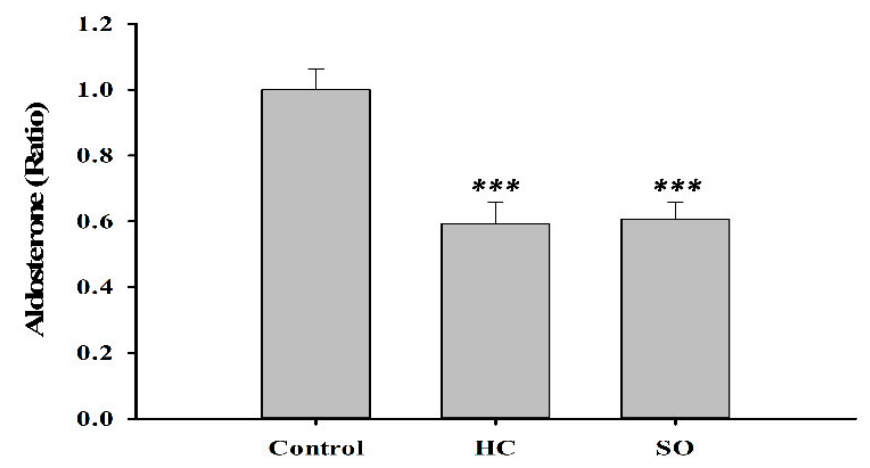

Figure 8. Aldosterone level in T2DM model rats after 28 days of treatment. Significant difference between the control-treated group at ${ }^{* * *} p<0.001$ by one-way ANOVA.

\section{Discussion and Conclusions}

In this study, we aimed to explore a natural product, $H$. coronarium, and determine if it would benefit people with diabetes. Two types of diabetic rodent models were used to determine the glycemia lowering effect of an aqueous extract of $H$. coronarium leaves. We found that HC significantly increased glucose tolerance in both diabetic models, improved the lipid profile, moderately increased insulin, benefited $\beta$-cell structure, and decreased the aldosterone level in an STZ-induced T2DM model. Although HC has been used as a folk medicine worldwide-as a diuretic and for the treatment of inflammation, hypertension, and diabetes-its mechanism of action is yet to be elucidated.

Previous studies have reported that the RAAS has played a major role in diabetes; aldosterone is significantly increased in primary hyperaldosteronism, diabetes, and other metabolic syndromes. An increase in aldosterone causes impaired glucose tolerance, decreased pancreatic $\beta$-cell function, and tissue insulin sensitivity $[31,34,35]$. Aldosterone is a mineralocorticoid hormone that is produced from cholesterol in the cortex of the adrenal gland. It interacts with the mineralocorticoid receptor (MR) to regulate blood pressure, water sodium, and potassium homeostasis [36]. In addition, it has genomic and non-genomic actions. The genomic actions occur through the binding of aldosterone to cytoplasmic MR, and the aldosterone-MR complex translocates to the nucleus and modulates nuclear transcription [37]. As for the rapid non-genomic action, aldosterone increases intracellular $\mathrm{Ca}^{2+}$ and protein kinase $\mathrm{C}(\mathrm{PKC})$ activation. In addition, aldosterone activates and stimulates $\mathrm{Na}^{+} / \mathrm{K}^{+}$-ATPase, $\mathrm{Na}^{+} / \mathrm{K}^{+} / 2 \mathrm{Cl}^{+}$, NHE1, and $\mathrm{NBCe} 1$ [38-40], and other pathways, such as the Mitogen-activated protein (MAP) kinases pathway, adenylate cyclase, tyrosine kinase, 
and cAMP-dependent protein kinase. Therefore, understanding the complete regulation of aldosterone biosynthesis will allow medicinal interventions for the management of hypertension, congestive heart failure, renal disease, and diabetes mellitus [41]. In this study, both HC and SO significantly decreased aldosterone levels and increased glucose tolerance in the STZ-induced T2DM model. These findings suggest that T2DM may be improved by alteration of the aldosterone levels, but more studies are recommended to understand the regulation of this pathway.

Flavonoids may play a role in many metabolic processes involved in T2DM, and Q3GA (also known as miquelianin) is a flavonol glucuronide. Q3GA has been proven to inhibit the production of reactive oxygen species (ROS), low-density lipoprotein (LDL) oxidation [42,43], act as an anti-inflammatory, and improve insulin resistance in skeletal cells [44]. Q3GA also inhibited angiotensin II (Ang II)-induced increases in the DNA binding activity of activator protein (AP)-1, a downstream transcription factor of c-Jun N-terminal kinases (JNK), composed of the c-Jun homo/heterodimer [45]. Angiotensin II interacts with the angiotensin receptor (AT1) membrane receptor that is coupled to cellular second messengers, it is important in the regulation of aldosterone secretion [46]. As Q3GA can reduce the effect of Ang II, it may also contribute to the regulation of aldosterone.

As we would like to develop a new supplement containing HC, we also examined the effect of SO in this study. RYR has been reported to exert anti-inflammatory, hypotensive, cholesterol-lowering, cardioprotective, anticancer, and osteogenic activities [47]. In a previous study, RYR extract (300 mg/ kg/day) was reported to decrease the FBG, increase insulin secretion, and protect islet cells in $\mathrm{db} / \mathrm{db}$ mice [48]. Therefore, we selected RYR for the development of a food supplement containing HC. When the two compounds were combined, we expected an additional effect. In the present study, we also tested the efficacy of SO. SO slightly lowered fasting blood glucose after 28 days of treatment in the STZ -induced T2DM model (Figure 4B). The glucose tolerance (Figure 4C,D) in the SO treatment group was moderately increased compared with that in the HC group after 28 days. However, no differences in insulin, aldosterone, and histopathological findings were observed when the SO group was compared with the HC group. We found that HC exerts beneficial effects in diabetes through modulation of the aldosterone level in the blood to improve glucose tolerance. SO may slightly assist in the improvement of glucose tolerance, although the supplement formula requires improvement. SO also showed effects in two animal models, however, the efficacy of SO in the $\mathrm{db} / \mathrm{db}$ model was not as strong as $\mathrm{HC}$. The $\mathrm{db} / \mathrm{db}$ model is known to have as defects in the leptin receptor, leading to increases in insulin and blood glucose, insulin resistance, and obesity [49]. In contrast, STZ is a DNA alkylating agent that targets $\beta$-cells [25-28]. As shown by the lipid profile in the STZ model, SO has the ability to ameliorate lipid markers, although not to the same extent as HC (Table 2). This explained how SO lowered the FBG and increased the glucose tolerance after 14 days of treatment, but was not as effective as $\mathrm{HC}$ during day $28 \mathrm{in} \mathrm{db} / \mathrm{db}$ model (Figure 3).

In summary, we treated two types of diabetic rodent models with $\mathrm{HC}$ and $\mathrm{SO}$, and found that both HC and SO exerted beneficial effects on T2DM. However, SO treatment did not show a significant difference compared with the $\mathrm{HC}$ treatment. The underlying mechanisms of $\mathrm{HC}$, and the interactions of HC and RYR combined, are not wholly investigated yet. Therefore, we suggest that HC could be a suitable candidate for the development of drugs and food supplements for the treatment of T2DM, but more studies should be performed in order to understand the profound mechanism.

Supplementary Materials: The following are available online at http:/ / www.mdpi.com/2072-6643/11/3/629/s1, Table S1: $p$-Value of oral glucose tolerance test (OGTT) after administrating Hedychium coronarium (HC) and SugarOut (SO) in STZ-induced type 2 diabetes model (T2DM; $N=8$ ); Table S2: Biochemistry analysis of STZ-T2DM after treating HC and SO for 28 days.

Author Contributions: Y.-W.C., C.-H.L. and J.-J.K. planned the experiments; P.-L.L., C.-H.T., and L.-S.T. performed the experiments; L.-S.T. performed data analysis and wrote the manuscript; J.-W.L. is the main pathologist. All authors reviewed the manuscript.

Funding: This study was sponsored by Vitnovo Inc. and the Ministry of Science and Technology of Taiwan (MOST106-2320-B-038-015-MY3, MOST107-2320-B-038-064). 
Conflicts of Interest: The authors declare no conflict of interest. The study design, operation, data analyses, and conclusions were not influenced by the sponsor.

\author{
Abbreviations \\ T2DM type 2 diabetes; \\ HDL high-density lipoproteins cholesterol; \\ LDL low-density lipoproteins cholesterol; \\ OGTT oral glucose tolerance test' \\ FBG fasting blood glucose
}

\title{
References
}

1. World Health Organization. The Top 10 Causes of Death. Available online: https://www.who.int/newsroom/fact-sheets/detail/the-top-10-causes-of-death (accessed on 24 May 2018 ).

2. Bajaj, H.S.; Zinman, B. Glucose lowering strategies for cardiac benefits: Pathophysiological mechanisms. Physiology (Bethesda) 2018, 33, 197-210. [CrossRef]

3. Kannel, W.B.; Hjortland, M.; Castelli, W.P. Role of diabetes in congestive heart failure: The Framingham study. Am. J. Cardiol. 1974, 34, 29-34. [CrossRef]

4. Kannel, W.B.; McGee, D.L. Diabetes and cardiovascular disease. The Framingham study. JAMA 1979, 241, 2035-2038. [CrossRef] [PubMed]

5. Petropoulos, I.N.; Green, P.; Chan, A.W.; Alam, U.; Fadavi, H.; Marshall, A.; Asghar, O.; Efron, N.; Tavakoli, M.; Malik, R.A. Corneal confocal microscopy detects neuropathy in patients with type 1 diabetes without retinopathy or microalbuminuria. PLoS ONE 2015, 10, e0123517. [CrossRef] [PubMed]

6. Yorek, M.A. Vascular impairment of epineurial arterioles of the sciatic nerve: Implications for diabetic peripheral neuropathy. Rev. Diabet. Stud. 2015, 12, 13-28. [CrossRef] [PubMed]

7. Javed, S.; Alam, U.; Malik, R.A. Treating diabetic neuropathy: Present strategies and emerging solutions. Rev. Diabet. Stud. 2015, 12, 63-83. [CrossRef]

8. Manski-Nankervis, J.A.; Thuraisingam, S.; Sluggett, J.K.; Kilov, G.; Furler, J.; O’Neal, D.; Jenkins, A. Prescribing of diabetes medications to people with type 2 diabetes and chronic kidney disease: A national cross-sectional study. BMC Fam. Pract. 2019, 20, 29. [CrossRef] [PubMed]

9. Schrijvers, G. Disease management: A proposal for a new definition. Int. J. Integr. Care 2009, 9, e06. [CrossRef] [PubMed]

10. Raveendran, A.V.; Chacko, E.C.; Pappachan, J.M. Non-pharmacological treatment options in the management of diabetes mellitus. Eur. Endocrinol. 2018, 14, 31-39. [CrossRef] [PubMed]

11. World Health Organization. Global Report on Diabetes; WHO: Geneva, Switzerland, 2016.

12. Perera, P.K.; Li, Y. Functional herbal food ingredients used in type 2 diabetes mellitus. Pharmacogn. Rev. 2012, 6, 37-45. [PubMed]

13. Van Thanh, B.; Dai, D.N.; Thang, T.D.; Binh, N.Q.; Anh, L.D.; Ogunwande, I.A. Composition of essential oils of four Hedychium species from Vietnam. Chem. Cent. J. 2014, 8, 54. [CrossRef] [PubMed]

14. Ibrahim, H. Hedychium; Backhuys Publisher: Leiden, The Netherlands, 2001; Volume 2, pp. $290-295$.

15. Ribeiro Rde, A.; de Barros, F.; de Melo, M.M.; Muniz, C.; Chieia, S.; Wanderley M das, G.; Gomes, C.; Trolin, G. Acute diuretic effects in conscious rats produced by some medicinal plants used in the state of São Paulo, Brasil. J. Ethnopharmacol. 1988, 24, 19-29. [CrossRef]

16. Ribeiro Rde, A.; Fiuza de Melo, M.M.; De Barros, F.; Gomes, C.; Trolin, G. Acute antihypertensive effect in conscious rats produced by some medicinal plants used in the state of São Paulo. J. Ethnopharmacol. 1986, 15, 261-269. [CrossRef]

17. Bhandary, M.J.; Chandrashekar, K.R.; Kaveriappa, K.M. Medical ethnobotany of the siddis of Uttara-Kannada District, Karnataka, India. J. Ethnopharmacol. 1995, 47, 149-158. [CrossRef]

18. Zhan, Z.J.; Wen, Y.T.; Ren, F.Y.; Rao, G.W.; Shan, W.G.; Li, C.P. Diterpenoids and a diarylheptanoid from Hedychium coronarium with significant anti-angiogenic and cytotoxic activities. Chem. Biodivers. 2012, 9, 2754-2760. [CrossRef] [PubMed]

19. Reuk-ngam, N.; Chimnoi, N.; Khunnawutmanotham, N.; Techasakul, S. Antimicrobial activity of coronarin D and its synergistic potential with antibiotics. Biomed. Res. Int. 2014, 2014, 581985. [CrossRef] [PubMed] 
20. Chen, J.C.; Hsieh, M.C.; Lin, S.H.; Lin, C.C.; Hsi, Y.T.; Lo, Y.S.; Chuang, Y.C.; Hsieh, M.J.; Chen, M.K. Coronarin $\mathrm{D}$ induces reactive oxygen species-mediated cell death in human nasopharyngeal cancer cells through inhibition of p38 MAPK and activation of JNK. Oncotarget 2017, 8, 108006-108019. [CrossRef] [PubMed]

21. Matsuda, H.; Morikawa, T.; Sakamoto, Y.; Toguchida, I.; Yoshikawa, M. Labdane-type diterpenes with inhibitory effects on increase in vascular permeability and nitric oxide production from Hedychium coronarium. Bioorg. Med. Chem. 2002, 10, 2527-2534. [CrossRef]

22. Li, F.; Sun, X.Y.; Li, X.W.; Yang, T.; Qi, L.W. Enrichment and separation of quercetin-3-O-beta-d-glucuronide from lotus leaves (nelumbo nucifera gaertn.) and evaluation of its anti-inflammatory effect. J. Chromatogr. B Anal. Technol. Biomed. Life Sci. 2017, 1040, 186-191. [CrossRef]

23. Food and Drug Administration. Guidance for Industry-Estimating the Maximum Safe Starting Dose in Initial Clinical Trials for Therapeutic in Adult Healthy Volunteers; Center for Drug Evaluation and Research, Ed.; Food and Drug Administration: Rockville, MD, USA, 2005.

24. BKS.Cg-Dock7m +/+ Leprdb/J; The Jackson Laboratory: Bar Harbor, ME, USA, 2019.

25. Szkudelski, T. The mechanism of alloxan and streptozotocin action in B cells of the rat pancreas. Physiol. Res. 2001, 50, 537-546.

26. Szkudelski, T. Streptozotocin-nicotinamide-induced diabetes in the rat. Characteristics of the experimental model. Exp. Biol. Med. (Maywood) 2012, 237, 481-490. [CrossRef]

27. Islam, M.S.; Wilson, R.D. Experimentally induced rodent models of type 2 diabetes. Methods Mol. Biol. 2012, 933, 161-174. [PubMed]

28. Ghasemi, A.; Khalifi, S.; Jedi, S. Streptozotocin-nicotinamide-induced rat model of type 2 diabetes. Acta Physiol. Hung. 2014, 101, 408-420. [CrossRef] [PubMed]

29. Shackelford, C.; Long, G.; Wolf, J.; Okerberg, C.; Herbert, R. Qualitative and quantitative analysis of nonneoplastic lesions in toxicology studies. Toxicol. Pathol. 2002, 30, 93-96. [CrossRef] [PubMed]

30. Akbarzadeh, A.; Norouzian, D.; Mehrabi, M.R.; Jamshidi, S.; Farhangi, A.; Verdi, A.A.; Mofidian, S.M.; Rad, B.L. Induction of diabetes by Streptozotocin in rats. Indian J. Clin. Biochem. 2007, 22, 60-64. [CrossRef] [PubMed]

31. Joseph, J.J.; Echouffo-Tcheugui, J.B.; Kalyani, R.R.; Yeh, H.C.; Bertoni, A.G.; Effoe, V.S.; Casanova, R.; Sims, M.; Correa, A.; Wu, W.C.; et al. Aldosterone, renin, and diabetes mellitus in African Americans: The jackson heart study. J. Clin. Endocrinol. Metab. 2016, 101, 1770-1778. [CrossRef]

32. Lovshin, J.A.; Lytvyn, Y.; Lovblom, L.E.; Katz, A.; Boulet, G.; Bjornstad, P.; Lai, V.; Cham, L.; Tse, J.; Orszag, A.; et al. Retinopathy and RAAS activation: Results from the Canadian study of longevity in type 1 diabetes. Diabetes Care 2019, 42, 273-280. [CrossRef] [PubMed]

33. Griffin, T.P.; Islam, M.N.; Blake, L.; Bell, M.; Griffin, M.D.; O'Shea, P.M. Effect of sodium glucose co-transporter-2 inhibition on the aldosterone/renin ratio in type 2 diabetes mellitus. Horm. Metab. Res. 2018, 51, 91-99. [CrossRef] [PubMed]

34. Mosso, L.M.; Carvajal, C.A.; Maiz, A.; Ortiz, E.H.; Castillo, C.R.; Artigas, R.A.; Fardella, C.E. A possible association between primary aldosteronism and a lower beta-cell function. J. Hypertens. 2007, 25, 2125-2130. [CrossRef] [PubMed]

35. Widimsky, J., Jr.; Sindelka, G.; Haas, T.; Prazny, M.; Hilgertova, J.; Skrha, J. Impaired insulin action in primary hyperaldosteronism. Physiol. Res. 2000, 49, 241-244. [PubMed]

36. Schmidt, B.M. Rapid non-genomic effects of aldosterone on the renal vasculature. Steroids 2008, 73, 961-965. [CrossRef] [PubMed]

37. Hermidorff, M.M.; de Assis, L.V.; Isoldi, M.C. Genomic and rapid effects of aldosterone: What we know and do not know thus far. Heart Fail. Rev. 2017, 22, 65-89. [CrossRef]

38. Alzamora, R.; Brown, L.R.; Harvey, B.J. Direct binding and activation of protein kinase C isoforms by aldosterone and 17beta-estradiol. Mol. Endocrinol. 2007, 21, 2637-2650. [CrossRef]

39. Mihailidou, A.S.; Mardini, M.; Funder, J.W. Rapid, nongenomic effects of aldosterone in the heart mediated by epsilon protein kinase C. Endocrinology 2004, 145, 773-780. [CrossRef] [PubMed]

40. Yoshida, T.; Shin-ya, H.; Nakai, S.; Yorimoto, A.; Morimoto, T.; Suyama, T.; Sakurai, M. Genomic and non-genomic effects of aldosterone on the individual variation of the sweat $\mathrm{Na}^{+}$concentration during exercise in trained athletes. Eur. J. Appl. Physiol. 2006, 98, 466-471. [CrossRef]

41. Bollag, W.B. Regulation of aldosterone synthesis and secretion. Compr. Physiol. 2014, 4, 1017-1055. [PubMed] 
42. Terao, J.; Yamaguchi, S.; Shirai, M.; Miyoshi, M.; Moon, J.H.; Oshima, S.; Inakuma, T.; Tsushida, T.; Kato, Y. Protection by quercetin and quercetin 3-O-beta-D-glucuronide of peroxynitrite-induced antioxidant consumption in human plasma low-density lipoprotein. Free Rad. Res. 2001, 35, 925-931. [CrossRef]

43. Moon, J.H.; Tsushida, T.; Nakahara, K.; Terao, J. Identification of quercetin 3-O-beta-D-glucuronide as an antioxidative metabolite in rat plasma after oral administration of quercetin. Free Rad. Biol. Med. 2001, 30, 1274-1285. [CrossRef]

44. Liu, K.; Mei, F.; Wang, Y.; Xiao, N.; Yang, L.; Wang, Y.; Li, J.; Huang, F.; Kou, J.; Liu, B.; et al. Quercetin oppositely regulates insulin-mediated glucose disposal in skeletal muscle under normal and inflammatory conditions: The dual roles of AMPK activation. Mol. Nutr. Food Res. 2016, 60, 551-565. [CrossRef] [PubMed]

45. Ishizawa, K.; Yoshizumi, M.; Kawai, Y.; Terao, J.; Kihira, Y.; Ikeda, Y.; Tomita, S.; Minakuchi, K.; Tsuchiya, K.; Tamaki, T. Pharmacology in health food: Metabolism of quercetin in vivo and its protective effect against arteriosclerosis. J. Pharmacol. Sci. 2011, 115, 466-470. [CrossRef]

46. Mulrow, P.J. Angiotensin II and aldosterone regulation. Regul. Pept. 1999, 80, 27-32. [CrossRef]

47. Patel, S. Functional food red yeast rice (RYR) for metabolic syndrome amelioration: A review on pros and cons. World J. Microbiol. Biotechnol. 2016, 32, 87. [CrossRef] [PubMed]

48. Wang, J.; Jiang, W.; Zhong, Y.; Lu, B.; Shao, J.; Jiang, S.; Gu, P. Xuezhikang attenuated the functional and morphological impairment of pancreatic islets in diabetic mice via the inhibition of oxidative stress. J. Cardiovasc. Pharmacol. 2014, 63, 282-289. [CrossRef] [PubMed]

49. Tao, Y.-X. Glucose Homeostatis and the Pathogenesis of Diabetes Mellitus, 1st ed.; Academic Press: Cambridge, MA, USA, 2014.

(C) 2019 by the authors. Licensee MDPI, Basel, Switzerland. This article is an open access article distributed under the terms and conditions of the Creative Commons Attribution (CC BY) license (http:/ / creativecommons.org/licenses/by/4.0/). 